\title{
Malignant Triton Tumor in a Child: Case Report and Literature Review
}

This article was published in the following Dove Press journal:

Cancer Management and Research

\author{
Ailing Zhao ${ }^{1-3, *}$ \\ Daling Ding ${ }^{4, *}$ \\ Xueqin $\mathrm{Li}^{\mathrm{I}-3}$ \\ Jiangtao Wang ${ }^{1-3}$
}

'Department of Infant Ward, Children's Hospital Affiliated of Zhengzhou

University, Zhengzhou, Henan 450018,

People's Republic of China; ${ }^{2}$ Department of Infant Ward, Henan Children's

Hospital, Zhengzhou, Henan 450018,

People's Republic of China; ${ }^{3}$ Department of Infant Ward, Zhengzhou Children's Hospital, Zhengzhou, Henan 4500 I8, People's Republic of China; ${ }^{4}$ Department of Neurosurgery, The First Affiliated Hospital of Zhengzhou University, Zhengzhou, Henan 450052, People's Republic of China

*These authors contributed equally to this work
Correspondence: Jiangtao Wang Department of Infant Ward, Children's Hospital Affiliated of Zhengzhou

University, Zhengzhou, Henan 4500I8,

People's Republic of China

Emailsyd2004@yeah.net
Objective: Malignant triton tumor (MTT) is a rare and devastating malignant peripheral nerve-sheath tumor, which shows rapid growth and poor clinical outcomes. Here, we reported a 2-year-old girl who was diagnosed as MTT, an overview of the literature was conducted to discuss the clinical features and optimal treatment strategies of MTT. Methods: We conducted an analysis of 42 patients from the PubMed, Medline, Embase and Web of Science databases for relevant articles published between 1938 and 2018.

Results: A 2-year-old girl died of tumor recurrence. Forty-two eligible cases of MTT in children (birth to 18 years; mean age, 8.3 years), the highest frequency of occurrence was in 12-16 years; and the male-to-female ratio was 1.7:1. Only 33 provided complete treatment details: 11 patients received treatment by surgery alone; 2 received both surgery and chemotherapy; 4 received both surgery and radiation therapy; 14 received surgery, chemotherapy, and radiation therapy; 1 case received chemotherapy and radiation therapy; and only 1 received supportive care. In the 33 cases, the average OS and 5-year OS probability were 23.9 months (range, $0.3-156$ months) and $27.5 \pm 4.3 \%$. There were significant differences between radiation therapy and patient survival $(\mathrm{p}<0.05)$, postoperative chemotherapy/radiation therapy and patient prognosis $(\mathrm{p}<0.05)$.

Conclusion: The clinical and histopathological features and therapeutic options for MTT are discussed in the light of published data. Further studies are needed to improve survival in children with this rare malignant tumor.

Keywords: malignant triton tumor, malignant peripheral nerve-sheath tumors, children, treatment strategies, prognosis

\section{Introduction}

Malignant triton tumor (MTT) is a histological subtype of malignant peripheral nerve-sheath tumors (MPNST) that contains rhabdomyoblasts. It is an extraordinarily rare and highly malignant tumor, to date approximately 170 cases of MTT have been reported. ${ }^{1-3}$ And, data on clinical features and optimal treatment strategies for MTT are rarely, so the tumor is associated with poor clinical outcome. 4

The average age of patients with MTT is 31.7 years, and the morbidity rates are approximately equal among men and women. The tumor usually occurs in the head, neck, and trunk. Thus far, the lack of information on the incidence of MTT in the literature has made the tumor unfamiliar to most pediatricians and surgeons. Here, we report an unusual case of MTT in a child, and discuss the clinical features of this tumor as well as its treatment and prognosis in children. 


\section{Case Report}

\section{Patient Case}

A 2-year-old girl presented with a large mass in the right shoulder, gradually increasing in size over 2 months. Upon physical examination, the patient was found to be normal. There were no signs of neurofibromatosis (NF), such as café au lait spots or subcutaneous nodules, or a family history thereof. Physical examination revealed an obvious, firm, subcutaneous, nontender, incompressible, and immobile mass measuring approximately $4.0 \times 3.0 \times 3.0 \mathrm{~cm}$ located on the medial side of the right shoulder. There was no palpable axillary lymphadenopathy. The findings of enhanced computed tomography revealed a large posterior mediastinal mass; the lesion was unevenly enhanced, and there was no clear boundary between the lesion and surrounding tissue. There was another nodular soft-tissue mass located at the tip and middle of the right lung, near the diaphragm (Figure 1A-D). A differential diagnosis of neurogenic tumor was made on the basis of imaging findings.
The patient underwent a wide range of laboratory investigations, the results of which were all negative.

The patient underwent surgery for tumor resection both for alleviating the symptoms and confirming the diagnosis. During surgery, the tumor was found to be located in the supraclavicular fossa; it was solid, oval in shape, and lacked a complete capsule. However, because a part of the tumor was wrapped around a nerve, the solid mass was only partially resected.

The resected tumor was hard and light red in color, with moderate blood supply. Histological findings of multiple sections revealed spindle cells with wavy nuclei and scattered or focal large cells that were round or elongated and contained abundant and deep eosinophilic cytoplasm. A few cells exhibited cross striations, and mitotic figures were scarce (Figure 2A).

Upon immunohistochemical staining, the spindle cells showed focal positivity for S-100 protein, while the large cells were positive for vimentin, myoglobin, and myogenin, with a Ki-67 proliferation index of $30 \%$. Both cell
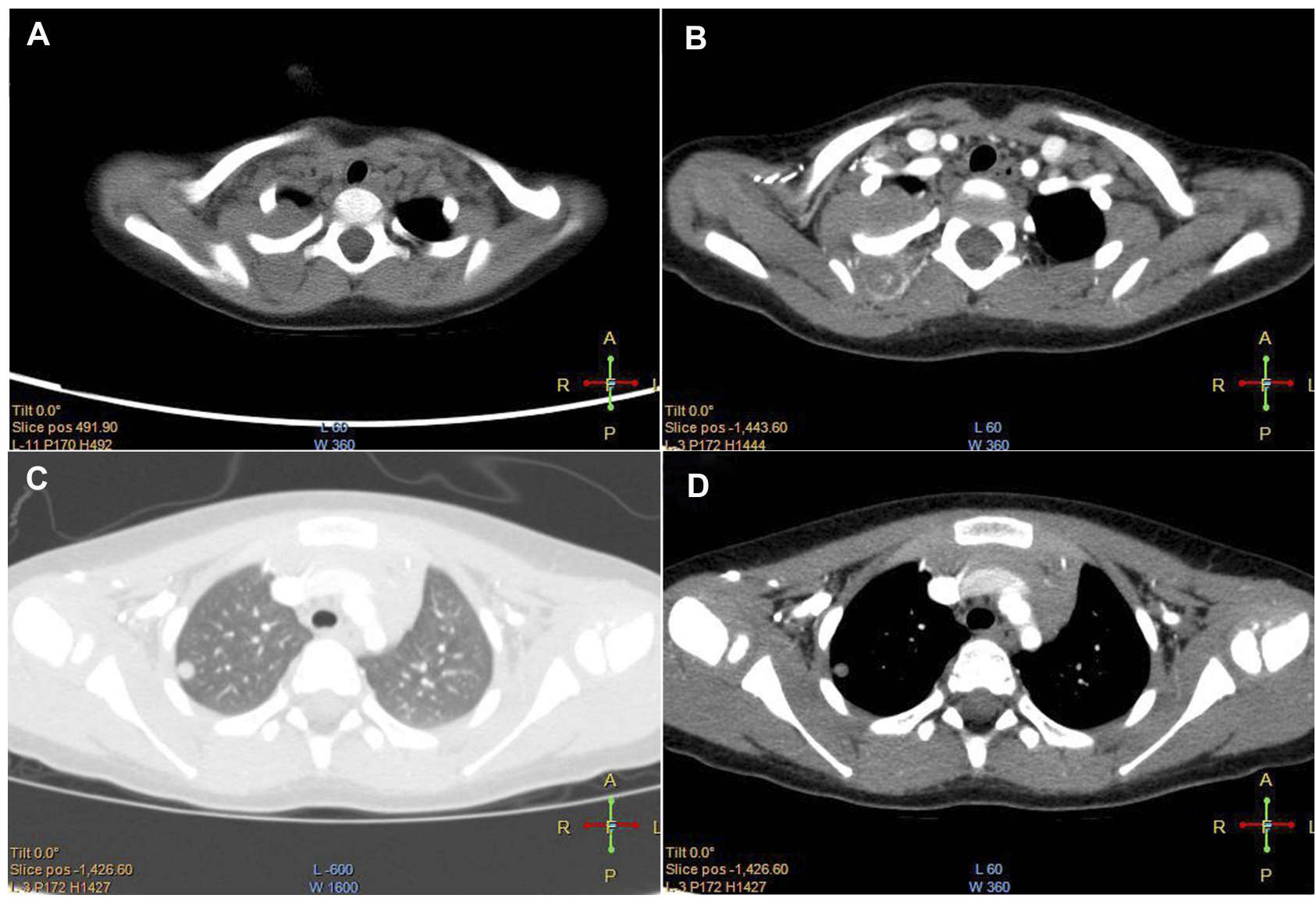

Figure I Preoperative image. (A) Axial unenhanced CT scan revealed a large posterior mediastinal mass. (B) The lesion was uneven enhanced. (C and D) There was another nodular soft tissue located in the right lung.

Abbreviation: CT, computed tomography. 

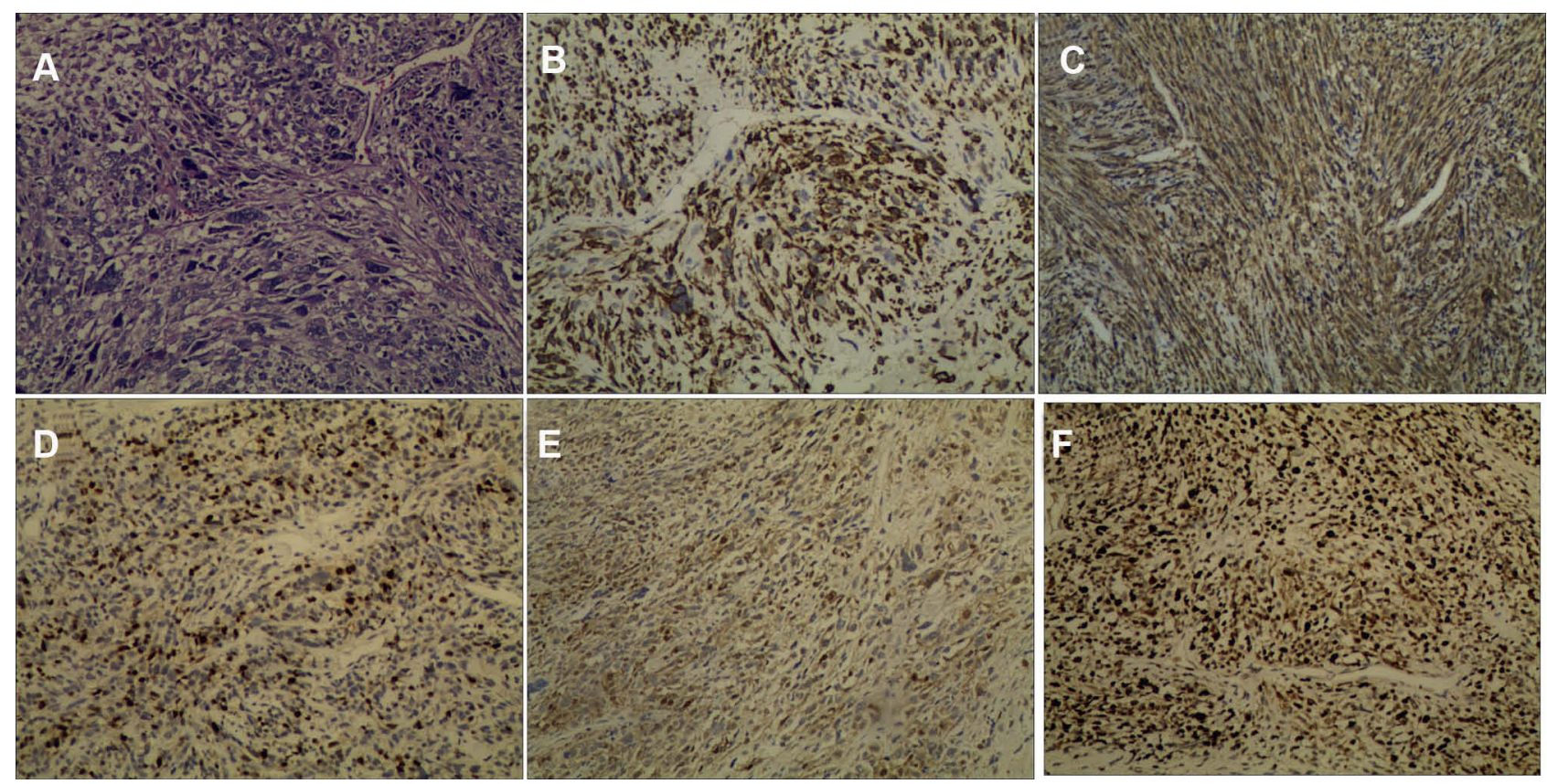

Figure 2 Immunostaining of the resected lesion. (A) Under the microscope, the tissue illustrated a remarkably uniform histological feature (hematoxylin and eosin, $\times 100)$. Immunohistochemical staining showed the tumor was strong positive for Desmin ( $\times 100)(\mathbf{B})$, Myoglobin $(\times 100)(\mathbf{C})$, Myogenin $(\times 100)(\mathbf{D})$, S-I00 ( $\times 100)(\mathbf{E})$, and Ki-67 $(\times 100)(\mathbf{F})$, which the Ki-67 index was $30 \%$. The tumor was negative for other markers.

types showed negative staining for glial fibrillary acidic protein, neuron-specific enolase, cytokeratin, epithelial membrane antigen, alpha-fetoprotein, CD30, SM-actin, and CD34 (Figure 2B-F). Therefore, on the basis of existing evidence and diagnostic criteria, a diagnosis of malignant peripheral nerve-sheath tumor with rhabdomyoblastic differentiation, i.e., MTT-was made. The diagnosis of MTT was mainly based on the histopathological and immunohistochemical characteristics of the tumor.

Although it is a highly malignant tumor, there is no standardized chemotherapy strategy for MTT currently. Therefore, we used the generally accepted multiagent MTT chemotherapy regimen, including vincristine, actinomycin, and cyclophosphamide, for treatment in the present case. The patient tolerated chemotherapy well. Although radiotherapy was also considered, her parents did not consent to it. Therefore, the patient was recommended continued chemotherapy. However, the patient died 14 months after surgery.

\section{Ethical Requirements}

This study protocol was approved by the Ethical Committee of the Zhengzhou University. Written informed consents were collected from all participants involved in the study. The patient's parents or legal guardians provided written informed consent for the case details and images to be published.

\section{Review of the Literature}

We searched the PubMed, Medline, Embase and Web of Science databases for relevant articles published between 1938 and 2017, using the following terms: "triton tumor", "rhabdomyosarcoma", and "malignant peripheral nerve sheath tumor". There was no exclusion for languages, details regarding patient characteristics was extracted from the articles. According to existing reports, KaplanMeier analysis was used and the log rank test was performed for comparison. The chi-square test was used to determine statistical significance, with $P<0.05$ being considered statistically significant. All statistical analyses were performed using the SPSS statistical software.

\section{Result}

Only 42 eligible cases of MTT in children (birth to 18 years; mean age, 8.3 years) were retrieved from available data, details regarding patient characteristics are summarized in Table 1. ${ }^{4-19}$ Among these 42 cases of MTT, the highest frequency of occurrence was in 12-16 years, and the male-to-female ratio was 1.7:1.

The treatment protocols were varied, and some patients received more than one type of therapy. Although there were 42 reported cases of MTT in children, only 33 (including the present report) provided complete treatment details (Table 1). In these 33 cases, 11 patients received 
Table I Characteristics, Treatment, and Outcome of Pediatric Patients with MTT

\begin{tabular}{|c|c|c|c|c|c|c|c|c|}
\hline Authors, Year & Age & Sex & Localization & NF-I & Surgery & Radiotherapy & Chemotherapy & Outcome \\
\hline Brooks et al, $1985^{19}$ & Congenital & $\mathrm{F}$ & Retroperitoneum & $N / A$ & Incomplete excision & 900 cGy & V, ACT, C & DOD I6wk \\
\hline Buck et al, $1977^{6}$ & Congenital & $\mathrm{F}$ & $\begin{array}{l}\text { Pelvic } \\
\text { retroperitoneum }\end{array}$ & NO & N/A & N/A & N/A & N/A \\
\hline Daimaru et al, $1984^{6}$ & $5 \mathrm{mo}$ & $\begin{array}{l}N / \\
A\end{array}$ & Urinary bladder & Yes & N/A & N/A & N/A & DOD 3mo \\
\hline Karcioglu et al, $1977^{4}$ & $6 \mathrm{mo}$ & $\mathrm{F}$ & Face & NO & Complete excision & 4500 cGy & $\mathrm{V}, \mathrm{ACT}, \mathrm{C}$ & NED I5mo \\
\hline Ellison et al, $2005^{4}$ & $11 \mathrm{mo}$ & M & Rectum & Yes & Complete excision & $(-)$ & $(-)$ & NED 3mo \\
\hline Fatma et al, $2006^{7}$ & $2 y$ & M & Pelvis & Yes & Complete excision & 3600 cGy & $\begin{array}{l}\text { V, ACT, C, IFO, } \\
\text { EPI, CARBO, } \\
\text { VPI6 }\end{array}$ & NED $8 \mathrm{mo}$ \\
\hline Present case & $2 y$ & $\mathrm{~F}$ & $\begin{array}{l}\text { Anterior } \\
\text { mediastinal }\end{array}$ & NO & Incomplete excision & $(-)$ & $\mathrm{V}, \mathrm{ACT}, \mathrm{CYC}$ & DOD $14 \mathrm{mo}$ \\
\hline Coffin et al, $1989^{8}$ & $3 y$ & $M$ & Occipital & Yes & $(+)$ & $(-)$ & $(-)$ & N/A \\
\hline Moran et al, $1997^{4}$ & $3 y$ & $\begin{array}{l}N / \\
A\end{array}$ & Lung & NO & $(+)$ & N/A & N/A & DOD 3mo \\
\hline Strauss et al, $1999^{\circ}$ & $3 y$ & $M$ & Right forearm & NO & $(+)$ & $(+)$ & $(+)$ & N/A \\
\hline $\begin{array}{l}\text { Bornstein-Quevedo } \\
\text { et al, } 2003^{4}\end{array}$ & $3 y$ & M & $\begin{array}{l}\text { Right parietal- } \\
\text { occipital lobe of } \\
\text { brain }\end{array}$ & NO & Incomplete excision & $(-)$ & $(-)$ & DOD IOd \\
\hline Chao et al, $2007^{10}$ & $3 y$ & M & $\begin{array}{l}\text { Left masticator } \\
\text { space }\end{array}$ & NO & $(-)$ & $70.2 \mathrm{~Gy}$ & $\begin{array}{l}\text { V, DOX, C, IFO, } \\
\text { ETO }\end{array}$ & AWD 3.6y \\
\hline Li et al, $2015^{5}$ & $43 \mathrm{mo}$ & M & $\begin{array}{l}\text { Right jugular } \\
\text { foramen area }\end{array}$ & NO & $(+)$ & $(-)$ & $(-)$ & AWD $7 \mathrm{mo}$ \\
\hline Inoue et al, $1980^{6}$ & $4 y$ & $M$ & Abdominal wall & Yes & N/A & N/A & N/A & N/A \\
\hline Daimaru et al, $1984^{6}$ & $4 y$ & $M$ & Abdominal wall & Yes & N/A & N/A & N/A & DOD $21 \mathrm{mo}$ \\
\hline Mallah et al, $2018^{\prime \prime}$ & $4 y$ & M & Trigeminal nerve & NO & Complete excision & 54Gy & EVAIA & AWD $22 \mathrm{mo}$ \\
\hline Glöckel et al, $1988^{4}$ & $5 y$ & $M$ & Pelvis & N/A & Incomplete excision & 5440 cGy & $\begin{array}{l}\text { ADR, C, V, DTI, } \\
\text { CDDP, VM26, } \\
\text { IFO, VPI6 }\end{array}$ & NED ly \\
\hline Nosaka et al, $1993^{12}$ & $5 y$ & M & Right foot & Yes & N/A & N/A & N/A & N/A \\
\hline Raney et al, $1978^{6}$ & $7 y$ & $M$ & Thigh & NO & N/A & N/A & N/A & NED $15 \mathrm{mo}$ \\
\hline $\begin{array}{l}\text { Schuangshoti et al, } \\
1979^{6}\end{array}$ & $8 y$ & $M$ & Forearm & NO & Complete excision & $(-)$ & $(-)$ & N/A \\
\hline Tang-Her et al, $2013^{13}$ & $8 y$ & $M$ & Cervical Spine & Yes & $(+)$ & 50Gy & ETO, PLA & DOD $19 \mathrm{mo}$ \\
\hline Ducatman et al, $1983^{14}$ & $9 y$ & $M$ & $\begin{array}{l}\text { Right Temporal } \\
\text { fossa }\end{array}$ & Yes & Incomplete excision & $(+)$ & $(+)$ & AWD $15 \mathrm{mo}$ \\
\hline Schmidt et al, $1990^{4}$ & $9 y$ & M & $\begin{array}{l}\text { Thenar } \\
\text { prominence }\end{array}$ & NO & Complete excision & 4000 cGy & $(-)$ & N/A \\
\hline Taxy et al, $1981^{6}$ & $10 y$ & $\mathrm{~F}$ & Face & NO & Incomplete excision & $(-)$ & $(-)$ & DOD $15 \mathrm{mo}$ \\
\hline Aldlyami et al, $2006^{15}$ & $11 y$ & M & Thigh & Yes & $(-)$ & $(-)$ & $(-)$ & Died 4mo \\
\hline
\end{tabular}

(Continued) 
Table I (Continued).

\begin{tabular}{|c|c|c|c|c|c|c|c|c|}
\hline Authors, Year & Age & Sex & Localization & NF-I & Surgery & Radiotherapy & Chemotherapy & Outcome \\
\hline Ducatman et al, $1984^{4}$ & $12 y$ & $\mathrm{~F}$ & Retroperitoneum & Yes & Complete excision & $(-)$ & $(-)$ & DOD I5mo \\
\hline Dewit et al, $1986^{4}$ & $12 y$ & M & Left calf & N/A & Incomplete excision & $(-)$ & $\begin{array}{l}\text { V, ACT, C, IFO, } \\
\text { ADR, MTX }\end{array}$ & DOD 19mo \\
\hline Victoria et al, $1999^{4}$ & $12 y$ & $\mathrm{~F}$ & $\begin{array}{l}\text { Infratemporal } \\
\text { fossa }\end{array}$ & NO & Incomplete excision & 5940 cGy & $\begin{array}{l}\text { VP-I6, IFO, V, C, } \\
\text { CDDP }\end{array}$ & DOD 30mo \\
\hline Brooks et al, $1985^{4}$ & $12 y$ & $\mathrm{~F}$ & Neck & Yes & Complete excision & 4400 cGy & $A D R, A C T, V$ & NED I $3 y$ \\
\hline Brtko et al, $2009^{16}$ & $12 y$ & M & $\begin{array}{l}\text { Thorax and } \\
\text { osteodystrofe } \\
\text { changes of } 3 \mathrm{rd} \\
\text { and } 4 \text { th costae }\end{array}$ & N/A & Incomplete excision & 56Gy & $\begin{array}{l}\text { V, IFO, ACT, } \\
\text { ETO, CAR, EPI }\end{array}$ & DOD 34mo \\
\hline Daimaru et al, $1984^{4}$ & $13 y$ & M & Facial nerve & NO & Complete excision & $(+)$ & $(+)$ & N/A \\
\hline Agustsson et al, $1955^{6}$ & $14 y$ & M & Thigh & Yes & N/A & $\mathrm{N} / \mathrm{A}$ & $\mathrm{N} / \mathrm{A}$ & DOD 20mo \\
\hline Cano et al, $2006^{4}$ & $14 y$ & $M$ & $\begin{array}{l}\text { Left sympathetic } \\
\text { nerve }\end{array}$ & NO & Complete excision & 3900 cGy & $(-)$ & DOD 3mo \\
\hline Isla et al, $2000^{4}$ & $15 y$ & M & $\begin{array}{l}\text { Thorax and } \\
\text { thoracic spine }\end{array}$ & Yes & Complete excision & $(-)$ & $(-)$ & DOD ly \\
\hline James et al, $2008^{4}$ & $15 y$ & $\mathrm{~F}$ & $\begin{array}{l}\text { Thorax and } \\
\text { thoracic spine }\end{array}$ & NO & Complete excision & $(+)$ & $(+)$ & DOD I6mo \\
\hline Yasuda et al, $2016^{3}$ & $15 y$ & $\mathrm{~F}$ & $\begin{array}{l}\text { The nasal } \\
\text { vestibule }\end{array}$ & NO & $(+)$ & 60Gy & $(-)$ & AWD 30mo \\
\hline Woodruff et al, $1994^{4}$ & $16 y$ & M & Tibial nerve & Yes & N/A & $\mathrm{N} / \mathrm{A}$ & N/A & $\mathrm{N} / \mathrm{A}$ \\
\hline McComb et al, $1996^{17}$ & $16 y$ & $\mathrm{~F}$ & Peroneal nerve & Yes & Incomplete excision & $\mathrm{N} / \mathrm{A}$ & $\mathrm{N} / \mathrm{A}$ & $\mathrm{N} / \mathrm{A}$ \\
\hline Otani et al, $1996^{4}$ & $17 y$ & $\mathrm{~F}$ & $\begin{array}{l}\text { Anterior } \\
\text { mediastinum }\end{array}$ & Yes & $(+)$ & 5000 cGy & $(-)$ & DOD 7mo \\
\hline Masson et al, $1938^{6}$ & $18 y$ & $\mathrm{~F}$ & Thigh & Yes & N/A & N/A & N/A & DOC $120 \mathrm{mo}$ \\
\hline Daimaru et al, $1984^{6}$ & $18 y$ & $\mathrm{~F}$ & Buttock & NO & N/A & $\mathrm{N} / \mathrm{A}$ & $\mathrm{N} / \mathrm{A}$ & DOD 43mo \\
\hline Koutsopoulos, $2011^{18}$ & $18 y$ & $\mathrm{~F}$ & $\mathrm{~N} / \mathrm{A}$ & Yes & Complete excision & 54Gy & IFO, ADM & AWD $5 y$ \\
\hline
\end{tabular}

Abbreviations: ACT, actinomycin; AWD, alive with disease; C, cytoxan; CARBO, carboplatin; CDDP, cisplatin; CYC, cyclophosphamide; DOC, died of other causes; DOD, dead of disease; EPI, epirubucin; ETO, etoposide; IFO, ifosfamide; N/A, nonapplicable; V, vincristine; $y$, years; mo, months; wk, weeks.

treatment by surgery alone; 2 received both surgery and chemotherapy; 4 received both surgery and radiation therapy; 14 received surgery, chemotherapy, and radiation therapy; 1 case received chemotherapy and radiation therapy; and 1 received supportive care only.

In the 33 cases that provided data on prognosis, the average OS and 5-year OS probability were 23.9 months (range, 0.3-156 months) and $27.5 \pm 4.3 \%$, respectively (Figure 3A). Postoperative radiotherapy had been administered in 16 cases, patients who received radiotherapy most often received radiation doses of 40-60 Gy. Furthermore, there was a significant difference in survival between patients whose treatment protocols did and did not include radiation therapy ( $P=0.001$, Figure 3B).

Patients described in these studies were often treated with postoperative chemotherapy alone or in combination with radiotherapy. Postoperative chemotherapy had been administered in 15 cases, and the chemotherapy regimens varied but often included V, ACT, C, ADR, IFO, etc. There was a statistically significant association between treatment protocols that did and did not include chemotherapy ( $P=0.012$, Figure $3 \mathrm{C}$ ).

Patients in these studies often received treatment by surgery alone or in combination with postoperative 
A

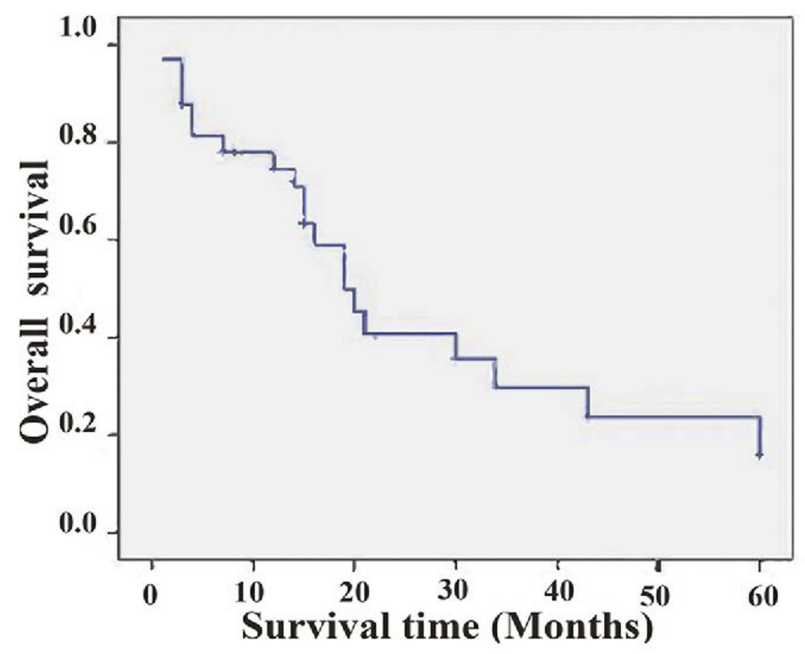

C

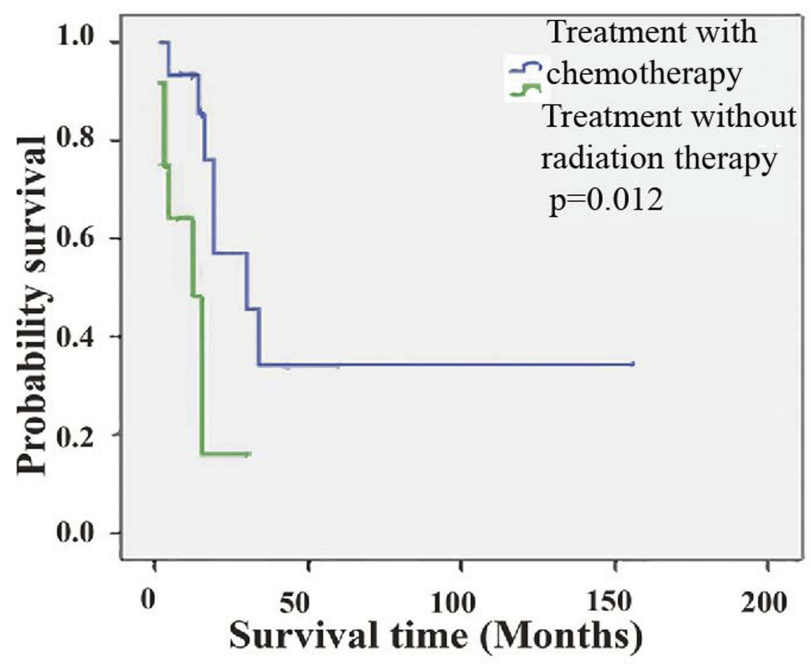

B

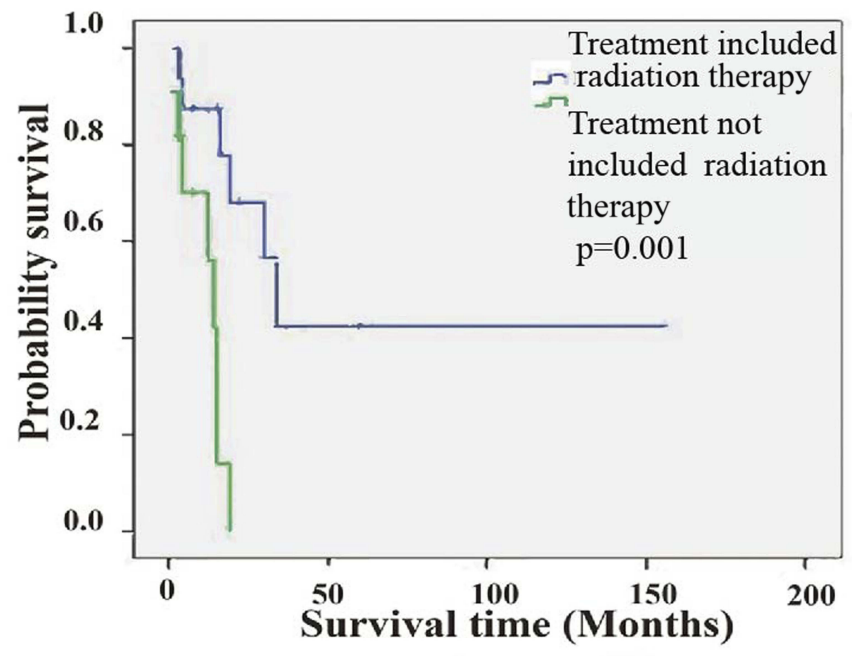

D

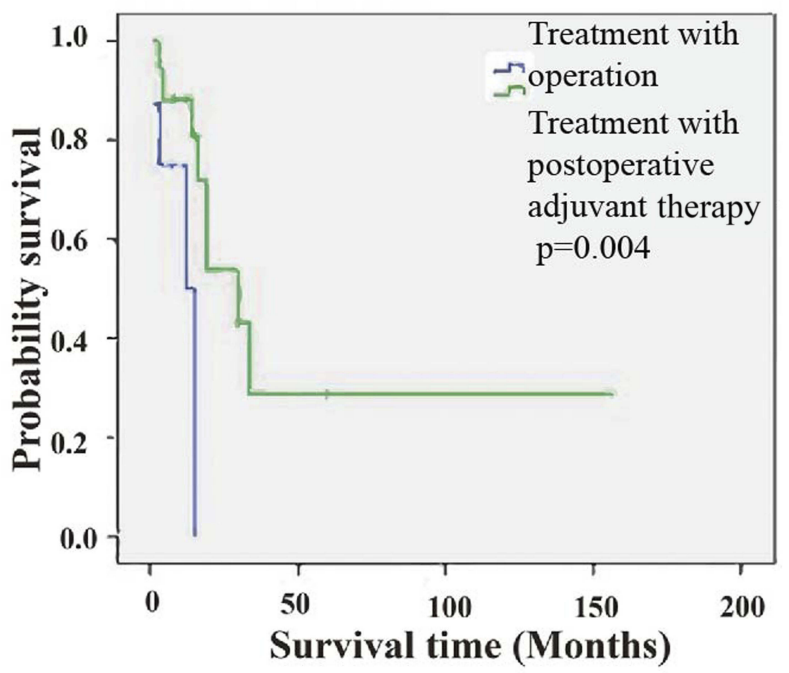

Figure 3 KaplanMeier survival analysis of the available data. (A) Overall survival. (B) Comparison of survival for patients who received radiation versus no radiation, $p=0.001$. (C) Comparison of survival for patients who received chemotherapy versus no chemotherapy, $p=0.012$. (D) Comparison of survival for patients who received operation only versus postoperative adjuvant therapy, $p=0.004$.

adjuvant therapy (including chemotherapy and/or radiation therapy). In eight cases, postoperative first-line treatment involved surgery. One of the patients, who had received postoperative chemotherapy and radiation therapy, was still alive 13 years after treatment. ${ }^{19}$ Patients who received postoperative chemotherapy and/or radiation therapy had a significant association with prognosis than those who received treatment by surgery alone ( $P=0.004$, Figure $3 \mathrm{D})$.

\section{Discussion}

Malignant triton tumor is a subgroup of MPNSTs which have been reported to exhibit rhabdomyosarcomatous differentiation and follow a particularly aggressive disease course. The diagnosis of MTT was mainly based on the histopathological and immunohistochemical characteristics of the tumor. It exhibits the growth characteristics of Schwann cells; rhabdomyoblasts can be demonstrated within the peripheral nerve tumor, but they do not originate from extension or metastasis of an extrinsic rhabdomyosarcoma. ${ }^{19}$ Daimaru et $\mathrm{al}^{6}$ later broadened the definition of MTT: 1) Tumors without NF-1 that are microscopically compatible with a malignant schwannoma and contain focal rhabdomyoblasts and 2) tumors consisting predominantly of rhabdomyoblastic differentiation with focal Schwann cell elements occurring within a nerve or in patients with NF-1. However, the cell type of origin of 
MTT remains unclear. Immunohistochemical staining helps demonstrate the origin of cells. There is a consensus that MTT can be diagnosed on the basis of morphological findings, supported by positive staining results for S-100 protein. ${ }^{16}$

Including the present case, only 42 such cases of MTT in children have been reported (Table 1). In this study, we have reported a case of MTT in a 2-year-old girl and reviewed the relevant literature. Comparison of clinical data among relevant studies is possible only to a limited degree, because MTT is a very rare tumor and has been reported either in single case reports, frequently with no or only scant data on treatment and follow-up, or as part of larger reports on MPNSTs. Moreover, the outcomes are not usually elaborated upon separately.

As the rarity of this entity and the lack of prospective trials, there is no standard treatment regimen for this rare tumor. The more popular treatments include radical excision only, radical excision followed by postoperative irradiation and chemotherapy, and excision in conjunction with radiotherapy. Data collected in the present literature review demonstrate that patients in previous reports received various types of therapy and had varying prognoses. We also found that postoperative radiotherapy, chemotherapy, and combined chemotherapy and radiotherapy could improve survival (Figure 3B-D).

Analysis of published reports on MTT revealed a trend towards better outcomes among patients undergoing complete tumor resection. Some authors have reported that complete tumor resection with or without adjuvant therapy tends to portend better survival than incomplete resection with or without adjuvant therapy. ${ }^{4}$ One of the patients, who had received postoperative chemotherapy and radiation therapy, was still alive 13 years after treatment.

The Oncology Consensus Group recommends postoperative radiotherapy as part of a uniform treatment policy for MTT. For patients who received radiotherapy for MTT in previous studies, the radiation doses varied considerably but were mostly between 40 and $60 \mathrm{~Gy}$, depending on the clinical context. ${ }^{3,12,15}$ It is worth noting that radiotherapy, as a part of primary treatment for MTT, seemed to have a positive effect on survival ( $P=0.001$, Figure $3 \mathrm{~B})$.

The value of chemotherapy for MTT remains questionable since published accounts of clinical experience are limited. Proposed chemotherapy regimens include CEI (cisplatin, etoposide, and ifosfamide) as first-line treatment and IA (ifosfamide and adriamycin) or MDID (mesna, doxorubicin, ifosfamide, and dacarbazine) as second-line treatment. In studies included in the present review, we also found a statistically significant association between treatment included chemotherapy and treatment did not include chemotherapy ( $P=0.012$, Figure $3 \mathrm{C})$. Thus, neoadjuvant chemotherapy potentially plays an important role in a multimodal treatment approach for a subset of patients with high-grade, metastatic, primarily unresectable MTT. ${ }^{5}$

\section{Conclusions}

Children with MTT have extremely poor prognosis, and optimal treatment strategies have yet to be established. When possible, complete tumor resection with adjuvant radiotherapy and/or chemotherapy should be recommended. We believe that the present findings will help attain a greater understanding of this rare tumor, but this study is limited due to the small sample size. Further research is required on the clinical behavior, tumor biology, and potential prognostic factors of MTT. Additionally, effective risk-adapted treatment recommendations and optimization of the balance between treatment intensity and adverse effects are needed.

\section{Abbreviations}

MTT, malignant triton tumor; MPNST, malignant peripheral nerve-sheath tumors; NF, neurofibromatosis.

\section{Acknowledgements}

This study was supported by grants from the Youth Foundation of The First Affiliated Hospital of Zhengzhou University and Henan Province's Natural Science Foundation (grant no.1 62300410311).

\section{Disclosure}

The authors declare no conflicts of interest in this work.

\section{References}

1. Ram R, Gardner J, Alapati S, et al. Malignant triton tumor (malignant peripheral nerve sheath tumor with rhabdomyoblastic differentiation) occurring in a vascularized free flap reconstruction graft. Int $J$ Surg Pathol. 2017;25(5):462-467. doi:10.1177/1066896917700725

2. Elleuch W, Briki S, Mnif H, Abdelmoula M. Malignant triton tumour of the maxilla: a case report. Eur Ann Otorhinolaryngol Head Neck Dis. 2018;135(4):297-298. doi:10.1016/j.anorl.2018.05.005

3. Yasuda M, Muto Y, Kuremoto T, et al. A case of recurrent malignant triton tumor successfully treated with radiotherapy. Auris Nasus Larynx. 2016;43(6):710-714. doi:10.1016/j.anl.2016.04.003

4. McConnell YJ, Giacomantonio CA. Malignant triton tumors-complete surgical resection and adjuvant radiotherapy associated with improved survival. J Surg Oncol. 2012;106(1):51-56. doi:10.1002/jso.v106.1

5. Li G, Liu C, Liu Y, et al. Analysis of clinical features and prognosis of malignant triton tumor: a report of two cases and literature review. Oncol Lett. 2015;10(6):3551-3556. doi:10.3892/ol.2015.3762 
6. Daimaru Y, Hashimoto H, Enjoji M. Malignant "triton" tumors: a clinicopathological and immunohistochemical study of nine cases. Hum Pathol. 1984;15(8):768-778. doi:10.1016/S0046-8177(84)80169-0

7. Fatma VO, Aynur O, Ceyda K, Caglar C, Pelin B, Oznur B. Malignant triton tumor of the pelvis in a 2-year-old boy. $J$ Pediatr Hematol Oncol. 2006;28(3):173-176. doi:10.1097/01.mph.0000201 419.05182.29

8. Coffin CM, Dehner LP. Peripheral neurogenic tumors of the soft tissues in children and adolescents: a clinicopathologic study of 139 cases. Pediatr Pathol. 1989;9(4):387-407.

9. Strauss BL, Gutmann DH, Dehner LP, Liapis H. Molecular analysis of malignant triton tumors. Hum Pathol. 1999;30(8):984-988. doi:10.1016/S0046-8177(99)90255-1

10. Chao MM, Levine JE, Ruiz RE, et al. Malignant triton tumor in a patient with Li-Fraumeni syndrome and a novel TP53 mutation. Pediatr Blood Cancer. 2007;49(7):1000-1004. doi:10.1002/pbc.20700

11. Mallah FA, Tanrıkulu B, Çorapçıŏlu F, Özek MM. Malignant triton tumor of trigeminal nerve-case report. Childs Nerv Syst. 2018;34 (5):983-986.

12. Nosaka S, Kao SC. MRI of malignant triton tumor in a child. Clin Imaging. 1993;17(1):53-55. doi:10.1016/0899-7071(93)90014-E.

13. Jaing TH, Chuang CC, Jung SM, Wu CT, Tseng CK, Chen CS. Malignant triton tumor of the cervical spine: report of one case and review of the literature. Pediatr Neonatol. 2015;56(1):58-61. doi:10.1016/j.pedneo.2013.01.013
14. Ducatman BS, Scheithauer BW, Piepgras DG, Reiman HM, llstrup DM. Malignant peripheral nerve sheath tumors. A clinicopathological study of 120 cases. Cancer. 1986;57(10):2006-2021. doi:10.1002/1097-0142(19860515)57:10<2006::AID-CNCR2820571022>3.0.CO;2-6

15. Aldlyami E, Dramis A, Grimer RJ, Abudu A, Carter SR, Tillman RM. Malignant triton tumor of the thigh- a retrospective analysis of nine cases. Eur J Surg Oncol. 2006;32(7):808-810. doi:10.1016/j.ejso.2006.04.008

16. Brtko J, Sejnová D, Ondková S, Macejová D. Malignant triton tumour exhibits a complete expression pattern of nuclear retinoid and rexinoid receptor subtypes. Gen Physiol Biophys. 2009;28 (4):425-427.

17. McComb EN, McComb RD, DeBoer JM, Neff JR, Bridge JA. Cytogenetic analysis of a malignant triton tumor and a malignant peripheral nerve sheath tumor and a review of the literature. Cancer Genet Cytogenet. 1996;91(1):8-12. doi:10.1016/S0165-4608(96)00125-2

18. Koutsopoulos AV, Mantadakis E, Katzilakis N, et al. Long-term survival of a patient with a neurofibromatosis Type 1 associated retroperitoneal malignant triton tumor after multi-modality treatment. Clin Neuropathol. 2011;30(6):333-335. doi:10.5414/ NP300393

19. Brooks JS, Freeman M, Enterline HT. Malignant "triton" tumors. Natural history and immunohistochemistry of nine new cases with literature review. Cancer. 1985;55(11):2543-2549. doi:10.1002/10970142(19850601)55:11<2543::AID-CNCR2820551105>3.0.CO;2-4

\section{Publish your work in this journal}

Cancer Management and Research is an international, peer-reviewed open access journal focusing on cancer research and the optimal use of preventative and integrated treatment interventions to achieve improved outcomes, enhanced survival and quality of life for the cancer patient.
The manuscript management system is completely online and includes a very quick and fair peer-review system, which is all easy to use. Visit http://www.dovepress.com/testimonials.php to read real quotes from published authors. 